\title{
THE
}

\section{REVISITING THE CLASSICS: CONSIDERING NONCONSUMPTIVE EFFECTS IN TEXTBOOK EXAMPLES OF PREDATOR-PREY INTERACTIONS}

\author{
Barbara L. Peckarsky \\ Peter A. Abrams \\ Daniel I. Bolnick \\ Lawrence M. Dill \\ Jonathan H. Grabowski
}

See next page for additional authors

Follow this and additional works at: https://digitalcommons.uri.edu/bio_facpubs

Terms of Use

All rights reserved under copyright.

\section{Citation/Publisher Attribution}

Peckarsky, B. L., Abrams, P. A., Bolnick, D. I., Dill, L. M., Grabowski, J. H., Luttbeg, B. , Orrock, J. L., Peacor, S. D., Preisser, E. L., Schmitz, O. J. and Trussell, G. C. (2008), REVISITING THE CLASSICS: CONSIDERING NONCONSUMPTIVE EFFECTS IN TEXTBOOK EXAMPLES OF PREDATOR-PREY INTERACTIONS. Ecology, 89: 2416-2425. doi:10.1890/07-1131.1 Available at: https://doi.org/10.1890/07-1131.1

This Article is brought to you for free and open access by the Biological Sciences at DigitalCommons@URI. It has been accepted for inclusion in Biological Sciences Faculty Publications by an authorized administrator of DigitalCommons@URI. For more information, please contact digitalcommons-group@uri.edu. 


\section{Authors}

Barbara L. Peckarsky, Peter A. Abrams, Daniel I. Bolnick, Lawrence M. Dill, Jonathan H. Grabowski, Barney Luttberg, John L. Orrock, Scott D. Peacor, Evan L. Preisser, Oswald J. Schmitz, and Geoffrey C. Trussell 


\title{
REVISITING THE CLASSICS: CONSIDERING NONCONSUMPTIVE EFFECTS IN TEXTBOOK EXAMPLES OF PREDATOR-PREY INTERACTIONS
}

\author{
Barbara L. Peckarsky, ${ }^{1,12}$ Peter A. Abrams, ${ }^{2}$ Daniel I. Bolnick, ${ }^{3}$ Lawrence M. Dill,${ }^{4}$ Jonathan H. Grabowski, ${ }^{5}$ \\ Barney Luttbeg, ${ }^{6}$ John L. Orrock, ${ }^{7}$ Scott D. Peacor,${ }^{8}$ Evan L. Preisser, ${ }^{9}$ Oswald J. Schmitz, ${ }^{10}$ \\ and Geoffrey C. Trussell ${ }^{11}$ \\ ${ }^{1}$ Department of Zoology, 453 Birge Hall, University of Wisconsin, Madison, Wisconsin 53706 USA \\ ${ }^{2}$ Department of Ecology and Evolutionary Biology, University of Toronto, Toronto, Ontario M5S3G5 Canada \\ ${ }^{3}$ Department of Biology, University of Texas, Austin, Texas 78705 USA \\ ${ }^{4}$ Department of Biological Sciences, Simon Fraser University, Burnaby, British Columbia V5A 1S6 Canada \\ ${ }^{5}$ Gulf of Maine Research Institute, 350 Commercial Street, Portland, Maine 04101 USA \\ ${ }^{6}$ Department of Environmental Science and Policy, University of California, Davis, California 95616 USA \\ ${ }^{7}$ National Center for Ecological Analysis and Synthesis, 735 State Street, Santa Barbara, California 93101 and \\ Department of Biology, Washington University, Saint Louis, Missouri 63130 USA \\ ${ }^{8}$ Department of Fisheries and Wildlife, Michigan State University, East Lansing, Michigan 48105 USA \\ ${ }^{9}$ Department of Biological Sciences, University of Rhode Island, Kingston, Rhode Island 02881 USA \\ ${ }^{10}$ School of Forestry and Environmental Studies, Yale University, 370 Prospect Street, New Haven, Connecticut 06511 USA \\ ${ }^{11}$ Marine Science Center, Northeastern University, 430 Nahant Road, Nahant, Massachusetts 01908 USA
}

Abstract. Predator effects on prey dynamics are conventionally studied by measuring changes in prey abundance attributed to consumption by predators. We revisit four classic examples of predator-prey systems often cited in textbooks and incorporate subsequent studies of nonconsumptive effects of predators (NCE), defined as changes in prey traits (e.g., behavior, growth, development) measured on an ecological time scale. Our review revealed that NCE were integral to explaining lynx-hare population dynamics in boreal forests, cascading effects of top predators in Wisconsin lakes, and cascading effects of killer whales and sea otters on kelp forests in nearshore marine habitats. The relative roles of consumption and NCE of wolves on moose and consequent indirect effects on plant communities of Isle Royale depended on climate oscillations. Nonconsumptive effects have not been explicitly tested to explain the link between planktonic alewives and the size structure of the zooplankton, nor have they been invoked to attribute keystone predator status in intertidal communities or elsewhere. We argue that both consumption and intimidation contribute to the total effects of keystone predators, and that characteristics of keystone consumers may differ from those of predators having predominantly NCE. Nonconsumptive effects are often considered as an afterthought to explain observations inconsistent with consumption-based theory. Consequently, NCE with the same sign as consumptive effects may be overlooked, even though they can affect the magnitude, rate, or scale of a prey response to predation and can have important management or conservation implications. Nonconsumptive effects may underlie other classic paradigms in ecology, such as delayed density dependence and predatormediated prey coexistence. Revisiting classic studies enriches our understanding of predatorprey dynamics and provides compelling rationale for ramping up efforts to consider how NCE affect traditional predator-prey models based on consumption, and to compare the relative magnitude of consumptive and NCE of predators.

Key words: behavior; consumptive effects; keystone predators; nonconsumptive effects; predator-prey cycles and interactions; trait-mediated indirect effects; trophic cascades.

\section{INTRODUCTION}

No ecology textbook would be considered complete without a discussion of the role of predators in ecological systems. As students of ecology, we are fascinated by the myriad ways predators search for and capture prey and the strategies prey adopt to avoid being captured. Yet ironically, much biological detail is

Manuscript received 10 July 2007; revised 3 December 2007; accepted 28 January 2008. Corresponding Editor: S. Naeem. For reprints of this Special Feature, see footnote 1, p. 2414.

${ }^{12}$ E-mail: peckarsky@wisc.edu often suppressed or technically abstracted when students are taught how to describe and model the dynamics of predator-prey interactions. Abstracting biological detail is arguably a matter not only of conventional perspective, but also of necessity. Textbook examples are generally selected for the clarity they provide for foundation principles, and consequently, invariably and perhaps necessarily ignore complexities. Simple theories are more effective in an educational context, because theories with too much mechanistic detail become unwieldy and may distract from the points being made in textbooks. 
Conventionally, predator-prey dynamics are described by quantifying changes in the numerical abundance of prey populations as a consequence of direct consumption by predators; and that perspective is buttressed in textbooks by examples for which authors have shown congruence between theory and empirical patterns of abundance. However, we know that predators can also have direct nonconsumptive effects (NCE) on prey populations by causing changes in prey traits, such as behavior, growth, and development (Lima 1998, Schmitz et al. 2004). NCE may be equally or more important than consumption to predator-prey population and community dynamics (Abrams 1990, Anholt and Werner 1995), often having associated indirect effects on other organisms in the community (e.g., Werner and Peacor 2003) and on ecosystem properties and functions (Schmitz et al. 2008). Notably, NCE also include changes in local prey abundance as a consequence of predator-induced prey dispersal or aggregation behavior (Sih and Wooster 1994). Therefore, one cannot assume that changes in local prey density in the presence of predators are caused by consumption. Furthermore, NCE may be additive or compensatory to consumption (decrease or increase local abundance), thereby conflating or confounding estimates of prey mortality. Consequently, overlooking the contribution of NCE of predators to prey population dynamics potentially changes the interpretation of classic textbook examples of predator-prey dynamics.

Our goal is to introduce a Special Feature on nonconsumptive effects of predators by broadening the scope of traditional, simplified explanations of predator effects on predator-prey cycles and food webs. Rather than updating previous comprehensive reviews of $\mathrm{NCE}$ (e.g., Lima 1998), we revisit familiar textbook examples so that students can gain an appreciation of the richer suite of effects of predators exhibited in natural systems. Understanding the full complexity of the effects of predators is not only interesting from a heuristic standpoint, but also important for predicting the consequences of human-accelerated environmental change (e.g., A. Sih, D. I. Bolnick, B. Luttbeg, J. L. Orrock, S. D. Peacor, L. M. Pintor, E. Preisser, J. Rehage, and J. R. Vonesh, unpublished manuscript). In addition, we emphasize the role of indirect effects of predators mediated by direct nonconsumptive effects on prey traits (i.e., trait-mediated indirect effects: TMIE: see review of terminology in Abrams [2007]), where relevant to the classic studies. Finally, we focus here on effects of predators, although nonconsumptive effects on prey traits also include responses to any sort of threat by another species (e.g., competitors).

We have selected examples of classic predator-prey studies often cited in general or theoretical ecology textbooks from which, in our collective experience, discussion of NCE are typically absent. In each case we ask how the subsequent consideration of nonconsumptive effects alters our understanding of population or community dynamics, implicitly providing criteria for updating or selecting new studies for future textbooks. We revisit four familiar cases based on natural observations and experiments and present strong empirical support for direct nonconsumptive effects of predators on prey population dynamics and associated trait-mediated indirect effects (lynx-hare population cycles [Elton and Nicholson 1942]; trophic cascades in north temperate lakes [Carpenter and Kitchell 1988]; population cycles and cascading effects of wolves on Isle Royale [Peterson et al. 1984]; trophic cascades in nearshore communities of the Aleutian Islands [Estes and Palmisano 1974]). We also encourage future studies to evaluate the potential for NCE to be important in two other classic predator-prey systems almost universally presented in textbooks as consumptive effects (size structure of freshwater zooplankton [Brooks and Dodson 1965]; effects of starfish on species diversity in the marine rocky intertidal [Paine 1966]). Given the insights gained by considering NCE and TMIE in those classic studies, we argue that studies of predator-prey interactions should routinely include this perspective.

\section{Predator and Prey Population Cycles: LynX AND SNOwshoe Hare}

One of the most widely recognized predator-prey dynamics is the sustained 10-year cycle of lynx (Lynx canadensis) and snowshoe hares (Lepus americanus) in northern boreal forests (Krebs et al. 2001). Despite recognition that adaptive responses to predation risk can drive population cycles (Abrams and Matsuda 1997, Yoshida et al. 2003), textbook accounts generally describe consumption by predators as the mechanism driving the dynamics. For example, a recent introductory ecology textbook summarizes the lynx-hare population cycles and associated indirect effects on plant resources as follows: "This potential decline [of the snowshoe hare population] is ensured and accelerated by high rates of mortality due to predation. As hare population density is reduced, predator populations decline in turn, plant populations recover, and the stage is set for another increase in the hare population" (Molles 2006:333).

While experiments have provided evidence that predators maintain the lynx-hare cycle (e.g., Krebs et al. 1995), it is becoming increasingly apparent that the dynamics are not driven solely by consumptive effects. Risk of predation by lynx can lead to altered hare foraging behavior and reduced physiological condition, which contributes to the population decline and delayed recovery of cyclic low-phase populations of snowshoe hares (Hik 1995). For example, Boonstra et al. (1998a) tested male and female hares for levels of glucocorticoids and other stress-related hormones associated with the hypothalamic-pituitary-adrenocortical (HPA) feedback system, which is integral to the vertebrate "fight or flight" response to an acute stressor. Levels of stress hormones in hares were significantly higher in individuals born 
during periods of high predator densities, compared to those born in periods of low predator density. This chronic stress was correlated with a $25-30 \%$ drop in per capita reproductive output, infertility, increased vulnerability to disease and loss of mass (reviewed in Boonstra et al. 1998a). Loss of mass during the height of the decline phase occurred even in experimental populations receiving supplementary food (Hodges et al. 2006), a result consistent with the hypothesis that high predation risk causes chronic stress in hares (Hik 1995). Furthermore, chronic stress associated with predation risk resulted in higher per capita predation rates during the decline phase of the hare cycle than during other phases, potentially accelerating the consumptive effects of lynx on hare populations (Boonstra et al. 1998a, O’Donoghue et al. 1998).

To completely understand the lynx-hare population cycles one must also explain the slow recovery of hare populations during the "low phase" of the cycle when predator densities are low (Cary and Keith 1979, Boonstra et al. 1998b). The observation that hare fecundity remains low for several years following periods of high predator density (Keith 1990, Stefan and Krebs 2001) suggests that females surviving highstress periods may suffer long-term physiological effects that reduce both their fecundity and the fitness of their offspring. This interpretation is supported by long-term data on the reproductive output of female hares trapped during high-stress (high predator density) and low-stress (low predator density) periods (Sinclair et al. 2001). Over a four-year period under identical laboratory conditions, the "high-stress" females consistently produced $<50 \%$ as many offspring per female per year as the "low-stress" females. Genetic differences between the populations were ruled out, implying that chronic stressors had lifelong negative impacts on hare reproduction and maternal effects on subsequent generations. Increased predation mediated by maternal stress and the extended NCE of predation risk on the juvenile phenotype thus slows the rate of recovery of hares from the low phase of the cycle (Boonstra et al. 1998b).

The observation that nonconsumptive effects of lynx on hare abundance were in the same direction as effects of consumption perhaps explains why NCE were overlooked for so long. While recent studies demonstrate that characteristics of the cycle, such as its period and the phase shift of predator and prey populations, are altered by NCE, it remains to be determined whether NCE are crucial to the very existence of the cycle. Nonetheless, the evidence for the cumulative influence of lynx on hare behavior, physiology, and life history should be added to textbook accounts of this predator-prey cycle.

\section{Cascading Effects of Top Predators in North Temperate Lakes}

Trophic cascades, the indirect effect of predators on plants mediated by herbivores (Paine 1980, Strong 1992, Polis et al. 2000), provide excellent textbook examples of how indirect effects propagate in communities via consumption of prey by predators. One of the classic trophic cascades comes from three lakes in northern Wisconsin, USA (Peter, Paul, and Tuesday Lakes [Carpenter and Kitchell 1988]), which contain relatively simple communities composed of phytoplankton, herbivorous zooplankton species (Cladocera), small planktivorous fish species ("minnows"; mostly Phoxinus eos, P. neogaeus, and Umbra limi), and a large, piscivorous fish (largemouth bass, Micropterus salmoides). Peter and Paul Lakes contained abundant bass, few minnows, many Cladocera, and low algal densities, as would be expected with a classic top-down control food chain. Tuesday Lake had lost its piscivores after a winter dieoff and was a mirror image of the other lakes: abundant minnows, scarce Cladocera, and dense algae.

A series of whole-lake experiments tested whether changes in top predators caused cascading effects that resulted in suppression or release of algal populations. Paul Lake was left undisturbed as a reference system. Piscivore-dominated Peter Lake and planktivore-dominated Tuesday Lake were reversed by transferring $90 \%$ of the bass from Peter to Tuesday, and $90 \%$ of the minnows from Tuesday to Peter. Those manipulations caused a "massive, sustained response in lower trophic levels" (Carpenter and Kitchell 1988:766). Newly piscivore-dominated Tuesday Lake experienced increased zooplankton size and reduced phytoplankton density, as expected with a classic cascade based on consumption (Carpenter et al. 1987), and consistent with effects of planktivorous fish on zooplankton body size (Brooks and Dodson 1965).

In marked contrast, Peter Lake, from which bass were removed and minnows were added, exhibited more surprising dynamics. Trophic cascade theory predicts that the minnows would eat the Cladocera, releasing algae from grazing. Instead, Cladocera "grew explosively" (Carpenter and Kitchell 1988:767) for a few months before declining dramatically. The resolution to this riddle lay in changes in fish behavior after bass removals. Despite the experimental reduction of bass densities by $90 \%$, enough bass remained to pose a significant predation risk to the introduced minnows. Minnows responded to that risk by shifting their habitat use from the open pelagic to safer, shallow littoral habitat, which released open-water zooplankton from predation expected after minnow addition (Carpenter et al. 1987). The later decline in zooplankton density was the result of another behavioral shift. Young-of-the-year bass normally take refuge in shallow vegetated habitats to avoid cannibalism by adults. Late in the summer, juvenile bass grew large enough to evade cannibalism, and so shifted into the open water, where they eventually consumed the zooplankton. Hence, adaptive behavior by both minnows and juvenile bass led to shifts in habitat use, causing unexpected indirect effects at lower trophic levels (TMIE). Behavior thus altered the community dynamics of the system, reversing the sign 
of effects expected from the classic perspective of trophic cascades driven by consumption.

To test the mechanisms of minnow behavioral changes observed in Peter Lake, a more detailed experiment was conducted in another Wisconsin lake (He and Kitchell 1990). Piscivorous northern pike (Esox lucius) were introduced to Bolger Bog, a small (1-ha) lake that previously contained a diverse community of planktivorous minnow species. Minnow density, distribution, and species composition were monitored for one year before the introduction as a baseline to evaluate subsequent community changes. Since major limnological variables were similar across the two-year study, community changes could be attributed to the effects of augmented predators. After the piscivore introduction, minnow density declined to $11 \%$ of its previous maximum. Although this decline is consistent with expectations of a consumptive effect, the authors showed that it was predominantly due to behavioral shifts in minnow habitat use, including emigration into the outflow stream draining the lake. Using data on the increased emigration rates and a bioenergetic model to estimate consumption rates by pike, $\mathrm{He}$ and Kitchell (1990) estimated that in the first month following the pike introduction, emigration accounted for a roughly 10 -fold greater biomass change in minnows than consumption by predators. In this case, the nonconsumptive effect caused changes in prey density in the same direction as that predicted by consumption, but dramatically increased the rate and probably increased the magnitude of the total effect of predators on prey abundance.

While understanding the mechanisms causing changes in prey abundance is not necessary if one is interested only in the magnitude of the direct effects of predators on prey decline, knowledge of mechanisms is important to models predicting the direct effects of predators under altered circumstances. Furthermore, the trait-mediated indirect effects of predators on other species in lakes and remote effects on downstream systems cannot be predicted without knowing whether the minnows are consumed or dispersed. This classic study provides an excellent model system for understanding the importance of including NCE in models of the effects of predators, and the consequences of incorrectly attributing changes in prey abundance to consumption.

\section{Cascading Effects and Population Cycles: the Isle Royale Ecosystem}

A terrestrial trophic cascade often described in textbooks involves the interaction of wolves (Canis lupus), moose (Alces alces), and balsam fir (Abies balsamea) on Isle Royale, Michigan, USA. Much effort has been devoted to chronicle the rise and fall in abundances of wolves and moose in over 50 years of study (Peterson and Vucetich 2001). Moose in this system play an integral role in ecosystem function because they are the principal prey of wolves (Peterson et al. 1984, Peterson and Vucetich 2001), and their heavy browsing on balsam fir and other woody species determines fir seedling establishment and sapling recruitment and growth (Brandner et al. 1990, McLaren and Peterson 1994, McLaren and Janke 1996). As such, this example includes both predator-prey cycles and indirect effects (Peterson et al. 1984, McLaren and Peterson 1994).

A simple consumptive perspective of this system was called into question when investigators began to look at drivers of dynamics that were extrinsic to the system (Post et al. 1999). Specifically, a cyclic weather phenomenon with a decadal trend in temperature, moisture, and winter snowfall, the North Atlantic Oscillation (NAO), influences the interaction between wolves and moose. During high snowfall winters wolves hunt in larger packs, which is a more efficient strategy when moose are encumbered by deep snow and have difficulty escaping their predators (Post et al. 1999). Moreover, moose aggregate under conifers along lakeshores where there is less snow accumulation, making it easier for wolves to locate and capture them, and more difficult for them to escape once encountered. Thus, under high snowfall conditions consumption by wolves initiates a trophic cascade by reducing moose populations to levels where moose cause very little damage to balsam fir (Post et al. 1999).

The role of consumption by wolves becomes diminished when NAO forcing causes snowfall levels to decline and moose can disperse more widely across the landscape during low snow winters. Hunting in large packs becomes inefficient for wolves, so they disaggregate into smaller packs and become confined to local territories. Moose population density remains high because moose are more effective at escaping wolf predation by fleeing or by seeking refuge habitats (Post et al. 1999). Thus, during low snowfall years the predominant effect of wolves on moose changes from consumptive to nonconsumptive as a consequence of a costly diet shift to lower-quality food associated with predator-avoidance behavior, especially by cows with calves (Edwards 1993). Furthermore, the indirect effect of wolves on plants via changing moose behavior initiates the trophic cascade (TMIE), because moose achieve sufficient abundance to suppress sapling tree recruitment, resulting in a more open forest canopy and an altered understory of shrub and herb species (McInnes et al. 1992).

This example represents a case where both consumptive and nonconsumptive effects are important to population cycles and to trait-mediated indirect effects of predators on lower trophic levels; but each mechanism predominates under different conditions. Moreover, the relative roles of each type of effect are not simply determined by prey behavior, but rather by a dynamical predator-prey game (sensu Lima 2002) in which both players adjust their behaviors in response not only to behaviors of the other players, but also to 
changes in the environment. Most recently, theoretical work suggests that the population cycles of wolves and moose on Isle Royale could be driven by climateinduced changes in moose life history traits coupled with density dependence, rather than by consumptive effects of predators on prey (Wilmers et al. 2007). While the long-term nature of this study enabled revelation of the role of climate on population cycles, understanding the causes of system dynamics required consideration of nonconsumptive effects, which should be added to future textbook accounts.

\section{Cascading Effects of Top Predators on Kelp Forests}

In marine environments, consumption of sea urchins by sea otters has a positive indirect effect on kelp forests, providing a classic example of a trophic cascade apparently driven by consumption (Estes and Palmisano 1974). In nearshore habitats near the Aleutian Islands where sea otters are rare, urchins are abundant and barrens persist because urchin grazing prevents the establishment of kelp forests. In contrast, consumption of urchins by sea otters releases recruiting kelp from grazing, thereby allowing the establishment of rich kelp forest habitat.

This trophic cascade has been altered by recent dramatic declines in sea otter populations beginning in the 1990s, attributed to shifts in the diets of killer whales (Estes et al. 1998, 2004). Perhaps the most intriguing part of this story is that the observed sea otter declines could have been caused by as few as four killer whales (Estes et al. 1998). Thus, a shift in the diet choice rather than the density of the apex predators initiated changes in the cascading effects of top predators on kelp forests in this system (trait-initiated effect [Abrams 2004]). Nonetheless, this cascade has been interpreted as driven by consumption of sea otters by killer whales rather than by a predator-induced shift in antipredator traits of sea otters.

In fact, Estes et al. (1998) ruled out several nonconsumptive effects that could have explained declining sea otter populations, including sea otter migration in response to killer whale predation risk, predator-mediated reduced foraging activity, and increased disease with higher predation risk. To the contrary, Laidre et al. (2006) demonstrated that the growth and body condition of Alaskan sea otters actually improved during the 1990s when they were exposed to predation risk by killer whales, compared to the 1970s when otter populations were much larger. Despite the significant predation risk imposed by killer whales, sea otters that are not consumed are doing quite well, an effect attributed to killer whale predation, which has relaxed the intensity of competition among sea otters.

Notably, while comprehensive work published on this system initially provided convincing evidence that indirect effects of killer whales on kelp forests are caused by consumption by predators, nonconsumptive effects of killer whales on sea otters have subsequently been observed, with some possible indirect consequences (J. A. Estes, personal communication). First, the distribution of otters has shifted markedly shoreward since the population declines in southwest Alaska began in the late 1980s or early 1990s. This response coincidentally moved the otters into very shallow water where they are not only at lower risk from attack, but also prey abundance is high and the cost of foraging is low, potentially explaining why body condition has improved. Second, adaptive sea urchin behavior in response to risk of predation by sea otters also contributes to the cascading effects on kelp. Watson (1993) showed that sea urchins dispersed away from damaged urchins that were discarded by foraging otters or experimentally broken on the sea floor, and kelp patches formed in areas vacated by sea urchins. Similarly, Konar and Estes (2003) have shown that adaptive urchin behavior modulates phase shifts between kelp and urchin-dominated community states.

The observation that nonconsumptive effects of killer whales on sea otters and sea otters on sea urchins are in the same direction as consumptive effects certainly made them harder to detect. Nonetheless, NCE in this system may increase the magnitude of cascading effects on kelp forests otherwise mediated by consumption. A remaining challenge is to quantify the relative contributions of consumption and adaptive behavioral shifts of consumers to trophic cascades observed in this system. Adaptive behavioral shifts (NCE) may also provide an alternative explanation for improvement in sea otter condition under increasing risk of predation.

\section{Other Classics Where Future Studies SHOuld InCLude NCE}

Two other examples of predator-prey systems almost universally included in ecology textbooks are the effects of size-selective predation on the composition of the plankton (Brooks and Dodson 1965), and the effects of starfish as "keystone" predators controlling the diversity of species in rocky intertidal communities (Paine 1966). We present them here briefly as cases where NCE potentially contribute to the total effects of predators, but have not yet been demonstrated to explain the patterns observed in either system.

Brooks and Dodson (1965) compared the body size distributions of zooplankton between lakes in Connecticut, USA, with and without natural populations of marine planktivorous fish (alewives), and chronicled changes in the zooplankton size distribution of one lake from 1942 to 1964, 10 years after introduction of alewives. Lakes lacking alewives had zooplankton with larger body sizes than lakes with alewives, which were dominated by species with smaller body forms. The authors postulated that size-selective predation by alewives eliminates the larger-bodied zooplankton, a consumptive explanation for zooplankton body size distributions that has been reinforced by textbooks. 
However, the authors did not rule out the potential roles of predator and prey behavior, explicitly when addressing exceptions to the general patterns of zooplankton size in lakes. One large species of zooplankton (Cyclops bicuspidatus thomasi) was common in lakes with alewives, and one of the smallest copepods (Diaptomus minutus) was not present in the alewife lakes. Those exceptions were intriguing and stimulated discussion of mechanisms other than size-selective predation to explain their distributions. The authors speculated that an ontogenetic niche shift by the large Cyclops species (immatures are limnetic and adults are benthic or littoral) might enable it to escape predation by planktivores feeding primarily in limnetic areas. Brooks and Dodson (1965) also proposed that the epilimnetic-feeding copepod Diaptomus minutus may lack behavioral responses to avoid alewife predation, and consequently is eliminated in those lakes despite its small size. Those speculations have yet to be tested rigorously.

Notably, nonconsumptive effects were invoked to explain unexpected results or those running counter to the general pattern; that is, when consumptive and nonconsumptive effects on prey body size had opposite signs. This example reinforces the assertion that nonconsumptive effects can be overlooked if their effects on prey communities do not differ from consumptive effects. As such, NCE should be investigated in cases other than those with unexpected patterns.

The term "keystone" species was first introduced by Paine (1969) to describe the effects of predatory starfish, Pisaster ochraceus, on the community structure of organisms competing for space in the exposed rocky intertidal environment along the Pacific coastline of North America. In the original classic study, Paine (1966) was struck by the remarkable impact of one species, which could control the local species diversity of the rocky intertidal food web by preferentially consuming the dominant competitor, the mussel Mytilus californianus. In the absence or after experimental removal of starfish, the mussel out-competed inferior species by monopolizing limited space. Consequently, species diversity and food web complexity were highest in the presence of the starfish. The suggestion that keystone predators could generate stability in systems along a wide range of complexity ran counter to the widely held notion that ecological complexity controlled community stability (MacArthur 1955).

While the keystone species concept is discussed in most ecology textbooks and has been applied to a wide variety of systems (Power et al. 1996), there has been some contention over defining a keystone species (e.g., Strong 1992, Mills et al. 1993). Paine (1971) argued that a keystone predator must influence the density of the local competitive dominant species, usually by preferential consumption. Similarly, investigators who have applied this concept (Power et al. 1996:609) proposed that "A keystone species is one whose effect is ... disproportionately large relative to its abundance," and has "high consumption rates relative to prey production and differential impacts on potential dominant species" (Power et al. 1996:614). Notably, an extensive review of examples of keystone species revealed that the mechanism of effect of keystone predators was almost exclusively consumption, with no examples of keystonepredator-induced modification of adaptive prey traits (Power et al. 1996: Table 1).

While consumptive effects of keystone predators may be common among marine, freshwater, and terrestrial habitats (Power et al. 1996), we suggest that predators may also have disproportionately large nonconsumptive effects on prey. Furthermore, if we assume that predators often scare more prey than they eat, we argue that the NCE of keystone predators may increase the spatial scale of prey response (Orrock et al. 2008). While it may be more common for predators to have NCE on the behavior of mobile prey species, they may also affect sessile species indirectly if predator-induced displacement of dominant competitors affects either the vulnerability or the competitive success of sessile subordinate species (R. T. Paine, personal communication).

It is therefore surprising that the potential for predators to have direct nonconsumptive keystone effects on the per capita growth rate of other species and consequent trait-mediated indirect effects has received so little attention. Instead, the focus has been on predator effects on prey survival due to direct consumption rather than effects on behavioral and developmental traits and distribution, which may have effects on the prey community as strong or stronger than those produced by consumption of prey by keystone species. For example, Menge et al. (1994) suggest that variation in prey recruitment may determine whether a predator has a keystone effect on prey populations, but they do not consider the possibility that predators can affect prey recruitment (e.g., Resetarits and Wilbur 1989). Clearly, textbook accounts of keystone predators should be updated to consider their total impact including both the effects of consumption and the many potential effects of intimidation on prey populations and communities.

\section{Discussion}

Revisiting classic studies of predator-prey systems has revealed some cases for which there is good evidence that NCE are fundamental to population or community dynamics (Table 1: lynx-hare; trophic cascades in Wisconsin lakes; and Isle Royale). In other cases new evidence provides a compelling rationale for ramping up efforts to distinguish the relative contributions of consumption and NCE to community dynamics (Table 1: cascades in the Aleutian Islands). Although the interpretation of some predator-prey systems may not change after consideration of NCE, consumptive and nonconsumptive effects (with associated trait-mediated 
TABLE 1. Summary of nonconsumptive effects (NCE) in textbook examples of predator-prey interactions.

\begin{tabular}{|c|c|c|c|}
\hline Study system & Key studies $\dagger$ & Response variables & Nonconsumptive effects \\
\hline Lynx-hare in boreal forests & $\begin{array}{l}\text { Boonstra et al. }(1998 a, b) \text {; } \\
\text { Krebs et al. }(2001)\end{array}$ & $\begin{array}{l}\text { predator and prey } \\
\text { population cycles }\end{array}$ & $\begin{array}{l}\text { predator-induced physiological stress } \\
\text { response: increases rate and magnitude } \\
\text { of prey decline; delayed density- } \\
\text { dependence: decreases rate of prey } \\
\text { recovery from low phase; NCE } \\
\text { qualitatively same direction as CE }\end{array}$ \\
\hline $\begin{array}{l}\text { Communities in northern } \\
\text { Wisconsin lakes (piscivores- } \\
\text { planktivores-zooplankton-- } \\
\text { phytoplankton) }\end{array}$ & $\begin{array}{l}\text { Carpenter and Kitchell } \\
\text { (1988); He and Kitchell } \\
\text { (1990); Carpenter et al. } \\
\text { (2001) }\end{array}$ & $\begin{array}{l}\text { trophic cascade; } \\
\text { trait-mediated } \\
\text { indirect effects }\end{array}$ & $\begin{array}{l}\text { predator-induced habitat shifts: reverses } \\
\text { the sign of effects expected via } \\
\text { consumption; or increases rate of } \\
\text { effect in same direction as CE }\end{array}$ \\
\hline $\begin{array}{l}\text { Wolves-moose on Isle Royale } \\
\text { (wolves-moose-balsam } \\
\text { fir) }\end{array}$ & $\begin{array}{l}\text { Post et al. (1999); } \\
\text { Wilmers et al. (2007) }\end{array}$ & $\begin{array}{l}\text { population cycles; } \\
\text { trophic cascade; } \\
\text { trait-mediated } \\
\text { indirect effects }\end{array}$ & $\begin{array}{l}\text { prey responses to predators depend on } \\
\text { climate: CE, under conditions of high } \\
\text { snowfall; NCE, under conditions of } \\
\text { low snowfall }\end{array}$ \\
\hline $\begin{array}{l}\text { Marine communities in the } \\
\text { nearshore habitats of the } \\
\text { Aleutian Islands (killer whales- } \\
\text { sea otters-sea urchins-kelp) }\end{array}$ & $\begin{array}{l}\text { Estes and Palmisano (1974); } \\
\text { Estes et al. (1998); Konar } \\
\text { and Estes (2003); J. A. Estes } \\
\text { (personal communication) }\end{array}$ & $\begin{array}{l}\text { trophic cascade; } \\
\text { trait-mediated } \\
\text { indirect effects }\end{array}$ & $\begin{array}{l}\text { ruled out killer whale-induced declines } \\
\text { in sea otter performance; sea otter } \\
\text { performance improves via adaptive } \\
\text { shifts to inshore locations (same sign); } \\
\text { sea urchins respond to tests damaged } \\
\text { by sea otters (same sign, increases } \\
\text { magnitude) }\end{array}$ \\
\hline
\end{tabular}

$\dagger$ Studies proposing or testing for nonconsumptive effects.

indirect effects) should be considered as alternative or complementary a priori hypotheses with the goal of expanding our approach beyond the traditional focus on consumption to explain predator-prey dynamics.

We use the conceptual framework of Power et al. (1996) to generalize about the potential for predators to have large nonconsumptive effects. We argue that the attributes of predators that are "keystone consumers" may be different than those that are "keystone intimidators." While "keystone consumers" should have high consumption rates relative to prey production, "keystone intimidators" should have effects on prey traits disproportionate to predator abundance. We propose the following attributes as a set of hypotheses deserving rigorous testing. (1) Keystone intimidators should have the potential for exerting strong selection pressure via consumption, i.e., should be dangerous predators, because the frequency of attacks influences the evolution of prey defenses (Abrams 1990, Anholt and Werner 1995; S. D. Peacor, B. L. Peckarsky, G. C. Trussell, and J. R. Vonesh, unpublished manuscript). (2) Keystone intimidators should emit reliable cues that indicate potential danger (B. Luttbeg, L. M. Dill, B. L. Peckarsky, E. Preisser, and A. Sih, unpublished manuscript). (3) The benefit of a predator-induced prey trait (increased survival) is greater than the cost of producing the defensive trait; that is, the behavior or life history adjustment is adaptive (Abrams 1990; S. D. Peacor, B. L. Peckarsky, G. C. Trussell, and J. R. Vonesh, unpublished manuscript). (4) Keystone intimidators affect performance (traits) of species that are potentially competitive dominants or are otherwise strong interactors in communities and ecosystems (Paine 1980, Power et al. 1996).
The cumulative nonconsumptive effects that have now been documented in the lynx-hare system may also influence the population dynamics of other predatorprey systems (Abrams and Matsuda 1997). For example, a review focusing on mammalian prey found that early exposure to chronic stress can have residual effects on the development of a prey individual throughout its life (Apfelbach et al. 2005). Similarly, Beckerman et al. (2002) argue that cumulative life history responses to risk of predation may be an important mechanism explaining delayed density dependence in a much wider range of organisms. Thus, maternal effects acting through predation risk may be the principal mechanism underlying the lag phase crucial for delayed-density dependence in population cycles (Ginzburg and Colyvan 2004).

Better understanding of nonconsumptive effects may inform other classic paradigms in ecology. For example, NCE can modify competitive interactions, such that predation risk ultimately forms the basis for prey species coexistence or exclusion (Grand and Dill 1999). One system in which that paradigm has been tested is desert rodent communities, which have long been a model system for ecologists interested in understanding the influence of competition on community structure (Brown et al. 1979). Striking patterns in body size, locomotion, and habitat use by North American desert rodents are often cited as evidence for the effects of competition in reducing niche overlap (Price 1978, Brown et al. 1979, Kotler 1984, Kotler and Brown 1988). A competing hypothesis is that predation risk promotes the distinct habitat partitioning observed in desert rodents (Kotler 1984, Brown and Kotler 2004). While there is considerable contention about the relative importance of predation risk and foraging gain as 
potential bases for coexistence of competing species (Price 1986, Brown 1989, Longland and Price 1991), examining NCEs has provided insights regarding a niche axis along which desert rodent communities may be structured. Notably, NCEs have been a part of the desert rodent story from early on, although in this case, and other studies focusing on predator-prey dynamics, their relative importance is unresolved.

Noticeably absent from the elaboration of the textbook examples presented in this study is a quantitative comparison of the relative contribution of consumptive and nonconsumptive effects to the total effects of predators. While quantitative estimates partitioning those effects are rare for these case studies (but see He and Kitchell 1990), several approaches have been implemented to make progress toward that ultimate goal. First, recent meta-analyses suggest that in two-level food chains, the magnitude of nonconsumptive effects of predators on prey demographics approached that of consumptive effects (Preisser et al. 2005: Table 1). Second, a cost-benefit approach using prey fitness as a common currency predicts the circumstances under which the ratio of $\mathrm{NCE}$ to $\mathrm{CE}$ should be very high (S. D. Peacor, B. L. Peckarsky, G. C. Trussell, and J. R. Vonesh, unpublished manuscript). Third, demographic analyses similar to those first described by Werner and Gilliam (1984) have estimated the relative contributions of $\mathrm{CE}$ and $\mathrm{NCE}$ using a common currency (prey population growth rates), concluding that $\mathrm{NCE}$ can range from negligible (effects of dragonflies on damselflies) to $90 \%$ (trout and stoneflies on mayflies) of the total effect of predators (McPeek and Peckarsky 1998). NCE can also be 16 times greater than $\mathrm{CE}$ in some zooplankton systems (Pangle et al. 2007). Fourth, experiments partitioning total effects of predators are rare (Peacor and Werner 2001, Trussell et al. 2006) because of the inherent difficulty of implementing treatments independently testing consumptive and nonconsumptive effects of predators. Furthermore, Abrams (2008) argues that nonlethal predator treatments typically used in experiments do not give an adequate measure of NCE; he makes a strong theoretical case for meeting the challenge of designing experiments to partition the mechanisms of total predator effects. Those four general approaches provide promise toward achieving the goal of quantifying the relative magnitude of consumptive and nonconsumptive effects of predators, and serve as guidelines for future research to incorporate into textbooks.

Also missing from the textbook examples described here are the quantitative tools needed for ecologists to incorporate NCE into predator-prey models. Future ecology textbooks should provide a discussion of predator-prey models that demonstrate the implications of including NCE on total effects of predators. As an example, Preisser and Bolnick (2008) have modified the classical Lotka-Volterra framework to include NCE. A variety of previous works have shown that adaptive behavioral responses to predators can have major effects on population and community dynamics. Models have shown that adaptive defense by prey is very often stabilizing, because increased predator abundance reduces effective prey availability, which tends to return predator numbers to their original level (Abrams 1984, Ives and Dobson 1987). In graphical analyses of predator-prey models, this type of prey defense implies that the predator isocline is no longer vertical, instead having a positive slope. This type of self-limitation also has major implications for top-down and bottom-up effects in food chains (Abrams and Vos 2003). In particular, the Oksanen et al. (1981) theory that productivity gradients change the abundances of trophic levels in a step-wise fashion is no longer valid. Adaptive prey defense has also been shown to increase the likelihood that the abundance of a predator population will actually increase when harvesting of that population is increased (Abrams and Matsuda 2005). Finally, most nonconsumptive effects have the potential to lead to trait-mediated indirect effects, which can have even more profound effects on the population dynamics of food chains (Abrams 1995).

We argue that incorporating behavior and other predator-induced trait changes into models and empirical studies of predator-prey interactions is not unwieldy, and provides a better context for evaluating the role of consumptive effects of predators on prey population and community dynamics. Our reevaluation of textbook examples has reinforced the perspective that understanding both consumptive and nonconsumptive effects of predators and their indirect consequences on other components of communities and ecosystems yields a richer view of those classic studies.

In summary, models of predator effects on prey populations and communities should incorporate nonconsumptive effects (e.g., Abrams 1990), and experimental tests of predator effects should compare NCE to $\mathrm{CE}$ to fully understand the effects of predators (Abrams 2008). Often nonconsumptive effects are not tested unless some counter-intuitive pattern is detected that can not be explained by consumption. The potential for missing NCE that do not change the sign of prey responses underscores the importance of incorporating such tests as a rule, rather than an afterthought to explain exceptions. Notably, NCE having the same sign as consumptive effects may nonetheless change the rate or magnitude of prey responses to predators (Table 1), or alter the spatial dynamics of predator-prey interactions (Orrock et al. 2008). Nonconsumptive effects may also easily be misinterpreted as bottom-up effects, which can lead to misdirected management and conservation actions. Distinguishing the mechanisms of predator effects thereby enables us to draw more robust conclusions about the direct and indirect effects of predators in natural systems. 


\section{ACKNOWLEDGMENTS}

This manuscript was improved by constructive comments from Rudy Boonstra, Steve Carpenter, Stan Dodson, Jim Estes, Jim Kitchell, Burt Kotler, Bob Paine, Jalena Pantel, Eric Post, David Post, Mary Price, Jane Watson, and two anonymous reviewers. This work was conducted as part of the "Does Fear Matter?" Working Group supported by the National Center for Ecological Analysis and Synthesis, a Center funded by NSF (Grant No. DEB-0072909), the University of California, and the Santa Barbara Campus. The co-authors of this paper are listed alphabetically.

\section{Literature Cited}

Abrams, P. A. 1984. Foraging time optimization and interactions in food webs. American Naturalist 124:80-96.

Abrams, P. A. 1990. The effects of adaptive behavior on the type-2 functional response. Ecology 71:877-995.

Abrams, P. A. 1995. Implications of dynamically variable traits for identifying, classifying, and measuring direct and indirect effects in ecological communities. American Naturalist 146: 112-134.

Abrams, P. A. 2004. Trait-initiated indirect effects in simple food webs: consequences of changes in consumption-related traits. Ecology 85:1029-1038.

Abrams, P. A. 2007. Defining and measuring the impact of dynamic traits on interspecific interactions. Ecology 88:25552562.

Abrams, P. A. 2008. Measuring the impact of dynamic antipredator traits on predator-prey-resource interactions. Ecology 89:1640-1649.

Abrams, P. A., and H. Matsuda. 1997. Prey adaptation as a cause of predator-prey cycles. Evolution 51:1742-1750.

Abrams, P. A., and H. Matsuda. 2005. The effect of adaptive change in the prey on the dynamics of an exploited predator population. Canadian Journal of Fisheries and Aquatic Science 62:758-766.

Abrams, P. A., and M. Vos. 2003. Adaptation, density dependence, and the abundances of trophic levels. Evolutionary Ecology Research 5:1113-1132.

Anholt, B. R., and E. E. Werner. 1995. Interaction between food availability and predation mortality mediated by adaptive behavior. Ecology 76:2230-2234.

Apfelbach, R., C. Blanchard, R. Blanchard, R. Hayes, and I. McGregor. 2005. The effects of predator odors in mammalian prey species: a review of field and laboratory studies. Neuroscience and Biobehavioral Reviews 29:1123-1144.

Beckerman, A., T. Benton, E. Ranta, V. Kaitala, and P. Lundberg. 2002. Population dynamic consequences of delayed life-history effects. Trends in Ecology and Evolution 17:263-269.

Boonstra, R., D. Hik, G. Singleton, and A. Tinnikov. 1998 a. The impact of predator-induced stress on the snowshoe hare cycle. Ecological Monographs 68:371-394.

Boonstra, R., C. J. Krebs, and N. C. Stenseth. 1998 b. Population cycles in mammals: the problem of explaining the low phase. Ecology 79:1479-1488.

Brandner, T. A., R. O. Peterson, and K. L. Risenhoover. 1990. Balsam fir on Isle Royale: effects of moose herbivory and population density. Ecology 71:155-164.

Brooks, J. L., and S. I. Dodson. 1965. Predation, body size, and composition of plankton. Science 150:28-35.

Brown, J. H., O. J. Reichman, and D. W. Davidson. 1979. Granivory in desert ecosystems. Annual Review of Ecology and Systematics 10:201-227.

Brown, J. S. 1989. Desert rodent community structure: a test of four mechanisms of coexistence. Ecological Monographs 59: $1-20$.

Brown, J. S., and B. P. Kotler. 2004. Hazardous duty pay and the foraging cost of predation. Ecology Letters 7:999-1014.
Carpenter, S. R., J. J. Cole, J. R. Hodgson, J. F. Kitchell, M. L. Pace, D. Bade, K. L. Cottingham, T. E. Essington, J. N. Houser, and D. E. Schindler. 2001. Trophic cascades, nutrients, and lake productivity: whole-lake experiments. Ecological Monographs 71:163-186.

Carpenter, S. R., and J. F. Kitchell. 1988. Consumer control of lake productivity. BioScience 38:764-769.

Carpenter, S. R., J. F. Kitchell, J. R. Hodgson, P. A. Cochran, J. J. Elser, M. M. Elser, D. M. Lodge, D. Kretchmer, X. He, and C. N. Vonende. 1987. Regulation of lake primary productivity by food web structure. Ecology 68:1863-1876.

Cary, J., and L. Keith. 1979. Reproduction change in the 10 year cycle of snowshoe hares. Canadian Journal of Zoology 57:375-390.

Edwards, J. 1993. Diet shifts in moose due to predator avoidance. Oecologia 60:185-189.

Elton, C. S., and M. Nicholson. 1942. The ten year cycle in numbers of the lynx in Canada. Journal of Animal Ecology 11:215-244.

Estes, J. A., E. M. Danner, D. F. Doak, B. Konar, A. M. Springer, P. D. Steinberg, M. T. Tinker, and T. M. Williams. 2004. Complex trophic interactions in kelp forest ecosystems. Bulletin of Marine Science 74:621-838.

Estes, J. A., and J. F. Palmisano. 1974. Sea otters: their role in structuring nearshore communities. Science 185:1058-1060.

Estes, J. A., M. T. Tinker, T. M. Williams, and D. F. Doak. 1998. Killer whale predation on sea otters linking oceanic and nearshore ecosystems. Science 282:473-476.

Ginzburg, L., and M. Colyvan. 2004. Ecological orbits: how planets move and populations grow. Oxford University Press, New York, New York, USA.

Grand, T. C., and L. M. Dill. 1999. Predation risk, unequal competitors and the ideal free distribution. Evolutionary Ecology Research 1:389-409.

He, X., and J. F. Kitchell. 1990. Direct and indirect effects of predation on a fish community: a whole-lake experiment. Transactions of the American Fisheries Society 119:825-835.

Hik, D. S. 1995. Does risk of predation influence population dynamics? Evidence from a decline of snowshoe hares. Wildlife Research 22:115-129.

Hodges, K. E., R. Boonstra, and C. J. Krebs. 2006. Overwinter mass loss of snowshoe hares in Yukon: starvation, stress, adaptation or artifact? Journal of Animal Ecology 75:1-13.

Ives, A. R., and A. P. Dobson. 1987. Antipredator behaviour and the population dynamics of simple predator-prey systems. American Naturalist 130:431-447.

Keith, L. 1990. Dynamics of snowshoe hare populations. Current Mammalogy 2:119-195.

Konar, B., and J. A. Estes. 2003. The stability of boundary regions between kelp beds and deforested areas. Ecology 84: 174-185.

Kotler, B. P. 1984. Risk of predation and the structure of desert rodent communities. Ecology 65:689-701.

Kotler, B. P., and J. S. Brown. 1988. Environmental heterogeneity and the coexistence of desert rodents. Annual Review of Ecology and Systematics 19:281-307.

Krebs, C., R. Boonstra, S. Boutin, and A. Sinclair. 2001. What drives the 10-year cycle of snowshoe hares? BioScience 51:2535.

Krebs, C., S. Boutin, R. Boonstra, A. Sinclair, J. Smith, M. Dale, K. Martin, and R. Turkington. 1995. Impact of food and predation on the snowshoe hare cycle. Science 269:11121115.

Laidre, K. L., J. A. Estes, M. T. Tinker, J. Bodkin, D. Monson, and K. Schneider. 2006. Patterns of growth and body condition in sea otters from the Aleutian archipelago before and after the recent population decline. Journal of Animal Ecology 75:978-989.

Lima, S. 1998. Non-lethal effects in the ecology of predatorprey interactions. BioScience 48:25-34. 
Lima, S. L. 2002. Putting predators back into behavioral predator-prey interactions. Trends in Ecology and Evolution 17:70-75.

Longland, W. S., and M. V. Price. 1991. Direct observations of owls and heteromyid rodents: can predation risk explain microhabitat use? Ecology 72:2261-2273.

MacArthur, R. H. 1955. Fluctuations of animal populations, and a measure of community stability. Ecology 36:533-536.

McInnes, P. J., R. J. Naiman, J. Pastor, and Y. Cohen. 1992. Effects of moose browsing on vegetation and litter of the boreal forest, Isle Royale, Michigan, USA. Ecology 73:20592075.

McLaren, B. E., and R. A. Janke. 1996. Seedbed and canopy cover effects on balsam fir seedling establishment in Isle Royale National Park. Canadian Journal of Forestry Research 26:782-793.

McLaren, B. E., and R. O. Peterson. 1994. Wolves, moose, and tree rings on Isle Royale. Science 266:1555-1558.

McPeek, M. A., and B. L. Peckarsky. 1998. Life histories and the strengths of species interactions: combining mortality, growth, and fecundity effects. Ecology 79:867-879.

Menge, B. A., E. L. Berlow, C. A. Blanchette, S. A. Navarrete, and S. B. Yamada. 1994. The keystone species concept: variation in interaction strength in a rocky intertidal habitat. Ecological Monographs 64:249-286.

Mills, L. S., M. E. Soule, and D. F. Doak. 1993. The keystonespecies concept in ecology and conservation. BioScience 43: 219-224.

Molles, M. 2006. Ecology: concepts and applications. Fourth edition. McGraw Hill, New York, New York, USA.

O'Donoghue, M., S. Boutin, C. Krebs, G. Zuleta, D. Murray, and E. Hofer. 1998. Functional responses of coyotes and lynx to the snowshoe hare cycle. Ecology 79:1193-1208.

Oksanen, L., S. D. Fretwell, J. Arruda, and P. Niemela. 1981. Exploitation ecosystems in gradients of primary productivity. American Naturalist 118:240-261.

Orrock, J. L., J. H. Grabowski, J. H. Pantele, S. D. Peacor, B. L. Peckarsky, A. Sih, and E. E. Werner. 2008. Consumptive and nonconsumptive effects of predators on metacommunities of competing prey. Ecology 89:2426-2435.

Paine, R. T. 1966. Foodweb complexity and species diversity. American Naturalist 100:65-75.

Paine, R. T. 1969. A note on trophic complexity and community stability. American Naturalist 103:91-93.

Paine, R. T. 1971. A short-term experimental investigation of resource partitioning in a New Zealand rocky intertidal habitat. Ecology 52:1096-1106.

Paine, R. T. 1980. Food webs: linkage, interaction strength and community infrastructure. Journal of Animal Ecology 49: 667-685.

Pangle, K. L., S. D. Peacor, and O. Johannsson. 2007. Large nonlethal effects of an invasive invertebrate predator on zooplankton population growth rate. Ecology 88:402-412.

Peacor, S. D., and E. E. Werner. 2001. The contribution of trait-mediated indirect effects to the net effects of a predator. Proceedings of the National Academy of Sciences (USA) 98: 3904-3908.

Peterson, R. O., R. E. Page, and K. M. Dodge. 1984. Wolves, moose, and the allometry of population cycles. Science 224: $1350-1352$.

Peterson, R. O., and J. A. Vucetich. 2001. Ecological studies of wolves on Isle Royale 2000-2001. Michigan Technical University Press, Houghton, Michigan, USA.
Polis, G. A., A. L. W. Sears, G. R. Huxel, D. R. Strong, and J. Maron. 2000. When is a trophic cascade a trophic cascade? Trends in Ecology and Evolution 15:473-475.

Post, E., R. O. Peterson, N. C. Stenseth, and B. E. McLaren. 1999. Ecosystem consequences of wolf behavioural response to climate. Nature 401:905-907.

Power, M. E., D. Tilman, J. A. Estes, B. A. Menge, W. J. Bond, L. S. Mills, G. Daily, J. C. Castilla, J. Lubchenco, and R. T. Paine. 1996. Challenges in the quest for keystones. BioScience 46:609-620.

Preisser, E. L., and D. I. Bolnick. 2008. The many faces of fear: comparing the pathways and impacts of nonconsumptive predator effects on prey populations. PLoS One 3(6):e2465.

Preisser, E. L., D. I. Bolnick, and M. F. Benard. 2005. Scared to death? The effects of intimidation and consumption in predator-prey interactions. Ecology 86:501-509.

Price, M. V. 1978. The role of microhabitat in structuring desert rodent communities. Ecology 59:910-921.

Price, M. V. 1986. Structure of desert rodent communities: a critical review of questions and approaches. American Zoologist 26:39-49.

Resetarits, W. J., Jr., and H. M. Wilbur. 1989. Oviposition site choice in Hyla chrysoscelis: role of predators and competitors. Ecology 70:220-228.

Schmitz, O. J., J. H. Grabowski, B. L. Peckarsky, E. L. Preisser, G. C. Trussell, and J. R. Vonesh. 2008. From individuals to ecosystem function: toward an integration of evolutionary and ecosystem ecology. Ecology 89:2436-2445.

Schmitz, O. J., O. Ovadia, and V. Krivan. 2004. Trophic cascades: the primacy of trait-mediated interactions. Ecology Letters 7:153-163.

Sih, A., and D. E. Wooster. 1994. Prey behavior, prey dispersal, and predator impacts on stream prey. Ecology 75:1199-1207.

Sinclair, A. R. E., D. Chitty, C. I. Stefan, and J. C. Krebs. 2001. Mammal population cycles: evidence for intrinsic differences during snowshoe hare cycles. Canadian Journal of Zoology $81: 216-220$.

Stefan, C., and C. Krebs. 2001. Reproductive changes in a cyclic population of snowshoe hares. Canadian Journal of Zoology 79:2101-2108.

Strong, D. R. 1992. Are trophic cascades all wet? Differentiation and donor control in speciose ecosystems. Ecology 73: 747-754.

Trussell, G. C., P. J. Ewanchuk, and C. M. Matassa. 2006. Habitat effects on the relative importance of trait- and density-mediated indirect interactions. Ecology Letters 9: $1245-1252$.

Watson, J. 1993. The effects of sea otter (Enhydra lutris) foraging on shallow communities off northwestern Vancouver Island, British Columbia. Dissertation. University of California, Santa Cruz, California, USA.

Werner, E. E., and J. F. Gilliam. 1984. The ontogenetic niche and species interactions in size-structured populations. Annual Review of Ecology and Systematics 15:319-341.

Werner, E. E., and S. D. Peacor. 2003. A review of traitmediated indirect interactions in ecological communities. Ecology 84:1083-1100.

Wilmers, C. C., E. Post, and A. Hastings. 2007. The perfect storm: the combined effects of autocorrelated environmental noise, age structure and density dependence on population fluctuations. American Naturalist 169:673-683.

Yoshida, T., L. E. Jones, S. P. Ellner, G. F. Fussman, and N. G. Hairston. 2003. Rapid evolution drives ecological dynamics in a predator-prey system. Nature 424:303-306. 